\title{
Educação escolar e o multiculturalismo intercultural: crítica a partir de Simone de Beauvoir
}

\author{
Sandra Soares Della Fonte ${ }^{*}$, Robson Loureiro
}

Resumo: O objeto de crítica deste artigo diz respeito a uma das perspectivas teóricas presentes no atual debate educacional: o multiculturalismo crítico ou intercultural. Analisamos o caráter sedutor do seu discurso para a educação escolar. A partir da contribuição teórica de Simone de Beauvoir, desvelamos que, apesar de seu ideal democrático, essa perspectiva desqualifica a escola e a intervenção dos professores, além de esfacelar o currículo escolar.

Palavras-chave: educação escolar; multiculturalismo; Simone de Beauvoir

\section{School education and the intercultural multiculturalism: critique from Simone de Beauvoir}

Abstract: This article approaches one of the theoretical perspectives of the contemporary educational debate: the critical or intercultural multiculturalism. It is here analysed the seductive character of its discourse for school education. Based on Simone de Beauvoir's theoretical contribution, this paper points out that, despite its democratic intentions, the critical or intercultural Multiculturalism disqualifies the school and the teachers' intervention, besides damaging the school curriculum.

Key words: school education, multiculturalism, Simone de Beauvoir

Em agosto de 1999, o Conselho de Educação do Estado do Kansas, nos EUA, proibiu a presença da teoria evolucionista nos currículos escolares do estado. A ação não chegou a proibir o ensino da evolução aos alunos; contudo, determinou que esses conhecimentos não estivessem presentes em testes finais. Essa resolução foi revogada em 2000. Entretanto, em 2005, o mesmo Conselho aprovou novas regras para o ensino de ciências, segundo as quais os professores deveriam assegurar o ensino da teoria da evolução das espécies junto com a teoria criacionista ou do Design inteligente ${ }^{1}$.

\footnotetext{
Professores e membros do Grupo de Estudos Marxistas em Educação e do Núcleo de Estudos e Pesquisas em Educação e Filosofia da Universidade Federal do Espírito Santo (UFES), Brasil. sdellafonte@uol.com.br, robbsonn@uol.com.br

I. A teoria do design inteligente foi elaborada, no final da década de 1980 nos EUA, por um grupo religioso, vinculado ao Center for Science and Culture do Discovery Institute; segundo suas explicações, haveria, no mundo, sinais de que ele foi projetado de modo inteligente e complexo por um designer igualmente inteligente e complexo (cf. Pieczarka, 2005).
} 
Também em 2005, em reação a essa decisão, um cidadão do Kansas, Bobby Henderson, protocolou, de modo satírico, naquele Conselho, um documento no qual protesta contra a redução do criacionismo a uma única vertente e pleiteia que a sua teoria religiosa - por ele denominada de Flying Spaghetti Monsterism - também tenha espaço na escola. Em sua carta aberta ao Conselho Estadual do Kansas, Henderson (2008, s.p.) afirma:

Estou escrevendo a vocês com muita preocupação, depois de ter lido suas audiências para decidir se a teoria alternativa do Design Inteligente deveria ser ensinada junto com a Teoria da Evolução. Eu acho que todos podemos concordar que é importante para os estudantes escutarem múltiplos pontos de vista para que, assim, possam escolher por eles próprios a teoria que faz mais sentido para eles. Estou preocupado, contudo, que os estudantes somente conhecerão uma Teoria do Design Inteligente.

Lembremo-nos que existem muitas teorias do Design Inteligente. Eu e muitos outros ao redor do mundo temos a forte crença de que o universo foi criado por um Monstro de Espaguete Voador. Foi Ele que criou tudo que podemos ver e tudo que podemos sentir. Acreditamos fortemente que toda a incontroversa evidência científica do mundo que indica um processo evolucionário não é nada além de uma coincidência, arquitetada por Ele.

Os eventos apresentados suscitam debates variados, mas um ganha especial destaque: diante de tão inusitados conflitos, como fica a situação da escola? Alguns estudos têm abordado essa questão por meio da necessária defesa política da escola laica (cf. Cunha, 2006, 2008). No entanto, várias tendências contemporâneas da produção do conhecimento em educação têm contribuído, a despeito de suas intenções, para tornar a instituição escolar vulnerável a esses conflitos. Em outras palavras, quando seus pressupostos são levados às últimas consequências, ao invés de fortalecer a função da escola de socializar, de modo laico, o patrimônio cultural elaborado, essas tendências a submetem ainda mais ao jogo de arbitrariedades. Para tratar a problemática posta, delineamos como objeto de crítica deste artigo uma dessas perspectivas teóricas presentes no atual debate educacional que, a nosso ver, ilustra tal situação: o multiculturalismo. Para tanto, recorremos às formulaçóes filosóficas da francesa Simone de Beauvoir. Em um primeiro momento, porém, o esforço reside em caracterizar o discurso multicultural e suas proposiçôes pedagógicas. 


\section{A sedução do discurso multicultural em relação à educação escolar}

O termo "multiculturalismo" é polissêmico e se vincula a posições políticas aparentemente distintas. Nesse sentido, mais do que multiculturalismo, haveria multiculturalismos.

A classificação realizada por McLaren (2000) tornou-se clássica. Segundo esse autor, o multiculturalismo pode ser: 1) conservador (próximo do legado colonialista de supremacia branca, exclui a noção de fronteira, boicota a educação bilíngue, etc.); 2) humanista liberal (baseado na noção de igualdade natural); 3) liberal de esquerda (essencializa as diferenças, independentemente da história, da cultura e do poder); e 4) crítico e de resistência (questiona a construção da diferença no contexto de relaçôes culturais e de poder), posição à qual McLaren diz se filiar.

Candau (2008) considera que o multiculturalismo pode ser visto ou como um traço da sociedade contemporânea (multiculturalismo descritivo), que assume configurações diferenciadas de acordo com o contexto histórico, político e sociocultural; ou como um horizonte de intervenção:

A perspectiva prescritiva entende o multiculturalismo não simplesmente como um dado da realidade mas como uma maneira de atuar, de intervir, de transformar a dinâmica social. Trata-se de um projeto, de um modo de trabalhar as relações culturais numa determinada sociedade e de conceber políticas públicas nessa direção. Uma sociedade multicultural constrói-se a partir de determinados parâmetros (Candau, 2008, p. 50).

Quanto às diferentes inspirações para esse tipo de resposta, a autora (2008) identifica os seguintes multiculturalismos: o assimilacionista; o diferencialista ou monoculturalismo plural; e o interativo, também denominado intercultural. Ela considera que este último, por ela adotado, assemelha-se à noção de multiculturalismo crítico de McLaren.

Já Moreira (2001, p. 66) considera que o

Multiculturalismo representa, em última análise, uma condição inescapável do mundo ocidental, à qual se pode responder de diferentes formas, mas não se pode ignorar. Multiculturalismo refere-se à natureza dessa resposta. Educação multicultural, consequentemente, refere-se à resposta que se dá a essa condição, em ambientes educacionais.

As respostas são variadas do ponto de vista político e, para Moreira, essa variedade deriva da compreensão que temos da diferença. 
Os autores citados explicitam não apenas a existência de multiculturalismos, como também de uma perspectiva multicultural crítica e intercultural. Devido ao fato de se associar, de imediato, ao campo de lutas políticas de intelectuais de esquerda, o multiculturalismo crítico é o interlocutor privilegiado neste artigo. Assim, cabe indagar suas características primordiais e a forma que sua argumentação ganha em termos de proposições pedagógicas. São essas questôes que abordamos a seguir.

Canen, Arbache e Franco (2001, p. 4) indicam que os estudos multiculturais em currículo e formação docente são aqueles que questionam "[...] mecanismos que silenciam e/ou interditam identidades com base em determinantes de gênero, etnia, classe social, raça, 'deficiência' física ou mental, padrões lingüísticos e culturais e assim por diante".

O multiculturalismo defendido por Moreira (2001, p. 67) compreende a diferença como uma construção social que

[...] pode e deve ser desafiada, em movimento que vise promover a aceitação do imperativo transcultural proposto por Boaventura de Sousa Santos (1997): as pessoas têm direito a serem iguais sempre que as diferenças as tornem inferiores; contudo, têm também o direito a ser diferentes sempre que a igualdade colocar em risco suas identidades.

Nesse contexto, ele sugere a substituição de multiculturalismo por interculturalismo, porque este segundo termo denota o caráter de relação dinâmica, reacomodações e reajustes entre as culturas (sua hibridização).

Da mesma maneira, Candau (2008, p. 51) posiciona-se, também baseada em Boaventura, a favor de "[...] um multiculturalismo aberto e interativo, que acentua a interculturalidade, por considerá-la a mais adequada para a construção de sociedades, democráticas e inclusivas, que articulem políticas de igualdade com políticas de identidade".

Dessa abordagem multicultural crítica e intercultural decorrem desdobramentos diversos para o campo educacional, que tangenciam temas como conhecimento escolar, formação de professores, pesquisa educacional, organização curricular, entre outros. Seguem-se alguns exemplos.

Em geral, essa tendência aponta que um dos desafios da escola é:

Em vez de preservar uma tradição monocultural, a escola está sendo chamada a lidar com a pluralidade de culturas, reconhecer os diferentes sujeitos socioculturais presentes em seu contexto, abrir espaços para a manifestação e valorização das diferenças (Moreira; Candau, 2003, p. 161).

Pro-Posiçóes, Campinas, v. 22, n. 3 (66), p. 177-193, set./dez. 2011 
Em outros termos,

A idéia é transformar a escola em um espaço de crítica cultural, de modo que cada professor(a), como intelectual que é, possa desempenhar o papel de crítico(a) cultural (Sarlo, 1999) e propiciar ao(à) estudante a compreensão de que tudo que passa por "natural” e "inevitável” precisa ser questionado e pode, conseqüentemente, ser transformado (Moreira; Candau, 2003, p. 163).

Moreira (2001) reage contra uma visão de multiculturalismo que promove, no ambiente escolar, festas, feiras, debates, comemorações — enfim, eventos episódicos para ressaltar traços de um grupo social:

Proponho, em contrapartida, que os conteúdos selecionados nas diversas disciplinas concorram para desestabilizar a lógica eurocêntrica, cristã, masculina, branca e heterossexual que até agora informou o processo e para confrontá-la com outras lógicas, com outras formas de ver e entender o mundo (Moreira, 2001, p. 76).

Para ele, não se trata de substituir os saberes hegemônicos por aqueles subalternizados e, sim, gerar a possibilidade de crítica e desconstrução social e cultural nos atritos e nas tensões entre as vozes hegemônicas e as dos sujeitos oprimidos.

Quanto a esse aspecto, Candau (2008, p. 52) defende

Uma educação para a negociação cultural, que enfrenta os conflitos provocados pela assimetria de poder entre os diferentes grupos socioculturais nas nossas sociedades e é capaz de favorecer a construção de um projeto comum, pelo qual as diferenças sejam dialeticamente integradas. A perspectiva intercultural está orientada à construção de uma sociedade democrática, plural, humana, que articule políticas de igualdade com políticas de identidade.

Nessa mesma direção, Macedo (2006, p. 289) indica a materialização dessa perspectiva em termos curriculares:

Penso nos currículos escolares como espaço-tempo de fronteira e, portanto, como híbridos culturais, ou seja, como práticas ambivalentes que incluem o mesmo e o outro num jogo em que nem a vitória nem a derrota jamais serão completas. Entendo-os como um espaço-tempo em que estão mesclados os discursos da ciência, da nação, do mercado, os "saberes comuns", as religiosidades e tantos outros, todos também híbridos em suas próprias constituições.

Pro-Posiçôes, Campinas, v. 22, n. 3 (66), p. 177-193, set./dez. 2011 
Para garantir essa mescla de discursos, a seu ver, é necessário reverter a colonização do híbrido Iluminismo/mercado que se impõe sobre os outros sistemas culturais, colonização na qual se encontram professor e aluno. Nesse sentido, ela registra:

[...] tanto professor como aluno convivem com a proposta colonial de substituição de saberes menos organizados (ou sincréticos) por outros com nível maior de organização (ou sintéticos). Falo, portanto, de um colonialismo de que somos todos agentes, em maior ou menor grau, em momentos diversos (Macedo, 2006, p. 292).

No horizonte da relação entre multiculturalismo e formação de professores como pesquisadores-reflexivos, Canen (2008, p. 302) observa que

Compreender, pois, o pesquisador como sujeito multicultural, que se afina com visões epistemológicas e ontológicas inerentes a paradigmas plurais de pesquisa, significa superar a ingenuidade sobre uma falsa neutralidade ou universalidade no ato de pesquisar e de ensinar, condição central de abertura para culturas e visões plurais, presentes na escola.

A autora ilustra sua posição ao defender a substituição da história pela narrativa histórica na metodologia da história documental. Ela insiste:

[...] fica evidente que a perspectiva multicultural de análise historiográfica, de estudos de caso e outras metodologias de pesquisa pode avançar no sentido de possibilitar a formação do professor pesquisador apto a analisar criticamente as metodologias de pesquisa e as fontes documentais em termos das narrativas aí produzidas, bem como capaz de inquirir sobre a invisibilidade ou o preconceito que atinge identidades étnicas, raciais, religiosas e outras, por meio da imersão nos contextos e pela participação ativa na produção de pesquisas, no seu contexto de formação (Canen, 2008, p. 305).

Dessa breve exposição, percebemos que o multiculturalismo crítico e intercultural possui um discurso sedutor, porque se constrói a partir dos seguintes traços que o colocam aparentemente no campo político das proposições pedagógicas de esquerda:

- as identidades são construções históricas que se engendram não em culturas isoladas, mas em contextos de interação e hibridização cultural; 
- esse processo não é harmônico, mas envolve assimetrias de poder, de tal modo que a particularidade de um grupo pode se impor sobre outros;

- o projeto de uma escola plural ou intercultural implica dar voz aos saberes e aos códigos culturais de grupos oprimidos para que se construam, no atrito com valores culturais hegemônicos, a crítica cultural e a possibilidade da mescla/integração dialética dos vários discursos;

- nesse horizonte, a educação escolar substitui a função de transmissão-assimilação do conhecimento elaborado e organizado, por uma postura de tensão e hibridização das várias narrativas e lógicas culturais;

- o tratamento das formas de conhecimento como narrativas colabora para a diluição da suposta rigidez entre cultura popular e erudita;

- o papel do professor consiste em potencializar a presença de uma multiplicidade de narrativas no contexto escolar, de modo a desconstruir qualquer pretensão de superioridade ou colonização de uma sobre outras;

- esse norte também é o eixo para a formação de professores e para a pesquisa educacional, além de servir de base para qualquer política de construção da igualdade e de uma sociedade democrática.

Se retornarmos ao problema inicial anunciado na primeira parte deste artigo, sob a ótica do multiculturalismo crítico e intercultural, a teoria da evolução das espécies necessitaria passar pela crítica cultural para evidenciar sua lógica e sua pretensão de verdade. Isso só poderia ocorrer na intersecção e no atrito com outras narrativas sobre a origem do universo e das espécies que foram silenciadas ao longo da história. Dessa tensão, novos saberes híbridos poderiam ser gerados, e a escola, então, cumpriria um papel de fomentar as interaçôes culturais a partir da garantia da igualdade das narrativas plurais e da afirmação das diferenças na construção do igualitarismo. Esse procedimento também valeria para a narrativa religiosa criacionista. Logo, a presença de outras narrativas culturais que desconstruam a monocultura do evolucionismo ou da religiosidade cristã, por exemplo, enriqueceria a possibilidade de crítica cultural e de descolonização do currículo escolar. Sendo assim, por seus próprios pressupostos, uma escola plural saudaria com satisfação a narrativa do Monstro do Espaguete Voador.

Será essa a alternativa contemporânea para a construção de uma educação escolar sintonizada com a construção da democracia e a superação das desigualdades sociais? Sem pretensão de dar conta, de modo pleno, dessa resposta, propomo-nos a oferecer algumas linhas de análise que visam problematizar o caráter sedutor desse discurso multicultural. 


\section{Uma intenção e uma inspiração}

Ao lançar essas perguntas, reconhecemos que, de modo imediato, corremos o risco de sermos rotulados de monoculturais ou colonialistas. Afinal, o que seria um educador que não fosse multicultural ou plural? Assim apresentado, o debate remete a uma situação delicada, pois, afinal: "Com esse tipo de convicção, ninguém poderia, em hipótese alguma, ser contrário à multiplicidade das culturas ou à necessidade de elaborar agendas educacionais ou políticas que as reconheçam" (Ahmad, 1999, p. 118).

Contudo, se tomamos o multiculturalismo crítico como uma proposição teórica, cujos fundamentos ultrapassam a mera defesa da multiplicidade cultural, podemos submetê-lo a escrutínio. Consideramos que há alguns elementos no multiculturalismo que contradizem o ideal democrático por ele anunciado. Isso se dá, na maior parte das vezes, à revelia das intençôes de seus propositores.

Para indicar aspectos dessa tese, recorremos à contribuição de uma intelectual considerada ícone dos estudos e das lutas feministas do século XX: a francesa Simone de Beauvoir (1908-1986). Beauvoir transitou dentro do existencialismo francês, perspectiva em relação à qual algumas restrições podem ser levantadas (cf. Lukács, 1979). Contudo, sua trajetória foi uma constante afirmação do papel do intelectual engajado, e essa atitude se materializou em várias de suas formulações filosóficas.

No diálogo crítico com essa escritora, lançamos mão de suas reflexões contidas no livro $O$ pensamento de direita hoje, por acreditar que há nele argumentos que podem ser apropriados para analisar algumas correntes teóricas contemporâneas, como o multiculturalismo. As ressalvas necessitam ser registradas, pois se trata de um ensaio originalmente publicado em 1955 na coletânea Privilégios, tendo como pano de fundo o fim da $2^{a}$ Guerra Mundial, o contexto de Guerra Fria e o conflito entre Sartre e Camus em torno do comunismo.

O objetivo de Beauvoir, nesse ensaio, é analisar o pensamento de direita de seu tempo sob vários aspectos (artístico, ético, político, filosófico, entre outros). A primeira frase do livro, que aparece na forma de epígrafe, já soa explosiva aos ouvidos atuais: "A verdade é una; o erro, múltiplo. Não é por acaso que a direita professa o pluralismo" (Beauvoir, 1972, s.p.) ${ }^{2}$.

Qualquer tentativa simplista de compreender tal assertiva compromete os argumentos da autora. Para quem já publicara, em 1949, O segundo sexo, livro de reconhecimento internacional no qual analisa a condição feminina, a afirmação inicial de Beauvoir em O pensamento de direita hoje não pode ser interpretada como

2. Esta citação e a seguinte, também de Beauvoir ( 1972), pertencem à epígrafe, inscrita em página não numerada. 
a defesa de projetos conservadores de homogeneização cultural. Se, por um lado, tal associação imediata deve ser evitada, por outro, irrompe a indagação: afinal, o que é esse pluralismo que, segundo Beauvoir, estava no coração do pensamento da direita na década de 1950? Aqui sintetizamos suas explicações.

O pensamento de direita se exprime em diversas e numerosas doutrinas que, segundo Beauvoir, não vacilam em lançar mão, de modo eclético, de argumentos de vários autores. Porém, os pensadores burgueses “[...] proíbem a seus adversários de utilizar os métodos de Marx se não aceitam em bloco todo o sistema deste" (Beauvoir, 1972, s.p.). O pensamento do teórico burguês representa, assim, um contrapensamento, pois "A primeira das suas preocupações é desembaraçar-se do marxismo" (Beauvoir, 1972, p. 13).

O otimismo burguês, tão presente no século XIX, foi abalado por uma atmosfera pessimista e catastrófica. No início do século XX, "A burguesia se pôs a duvidar das ilusões que ela própria forjara: os progressos da técnica e da indústria se revelaram mais ameaçadores do que promissores: aprendeu-se não a fertilizar a terra, mas a devastá-la" (Beauvoir, 1972, p. 3). Ela, a burguesia, se tornou vítima dos princípios que ela mesma ajudou a criar: justiça, igualdade de direitos, etc., valores e ideais engendrados quando era uma classe ascendente. Por essa razão: "Ela não pode renegar inteiramente esta filosofia das luzes cuja verdade pôde comprovar na Revolução Francesa” (Beauvoir, 1972, p. 9). Desse modo, o burguês assume uma postura ambivalente ante o pensamento; ele desconfia dos intelectuais, "[...] desconfia do próprio pensamento" (Beauvoir, 1972, p. 9). Essa postura anti-intelectualista, contudo, não invalida a sua necessidade de teóricos que justifiquem o seu domínio.

Beauvoir observa que, para o pensamento de direita, os problemas são questões de opinião; em outros termos, remetem ao sujeito, de tal modo que "A realidade material dos homens e da sua situação, não conta” (Beauvoir, 1972, p. 15). A diluição da objetividade permite a arbitrariedade plural das interpretações:

Privadas, tanto de presença quanto de existência, as coisas não são absolutamente nada. A partir daí, cada qual pode florear à sua maneira no céu inteligível. Temos direito de traçar nele relações ideais que não correspondem a nenhuma encarnação terrestre (Beauvoir, 1972, p. 61).

O pensamento burguês adota o pluralismo "como uma verdade definitivamente adquirida" (Beauvoir, 1972, p. 50). Assim, fala-se de escravidões, feudalismos, capitalismos, cada um desses fenômenos com uma história própria, que o fez diferir de si mesmo e dos demais. Nessa lógica, "Ao esquema 'simplista' de Marx, que opõe exploradores e explorados, se substitui um desenho tão complexo, que os opressores entre si diferem tanto quanto diferem dos oprimidos, a tal ponto que esta última distinção perde sua importância” (Beauvoir, 1972, p. 50). 
Para a autora, o pluralismo contorna a dificuldade que ele próprio suscita por meio da substituição do ideal de universalidade para uma multiplicidade de verdades. Isso é feito, pois, "Se a verdade fosse universalmente demonstrável, o pensamento estaria democraticamente aberto a todos: assim, substituem as relações rigorosas, necessárias, que a ciência estabelece, por relaçôes tênues e contestáveis" (Beauvoir, 1972, p. 59). Por isso, a elite estabelece uma relação paradoxal com a ciência: "A burguesia crê na ciência: seus ideólogos a contestam" (Beauvoir, 1972, p. 111). Os ideólogos de direita, por exemplo, dão uma interpretação fantasiosa do princípio da indeterminação, ao afirmarem que a matéria é desordem e contingência. Além de sucumbir ao deslize realista de dizer o que a realidade é, Beauvoir (1972, p. 56-67) indica a razão da atitude paradoxal com a ciência:

[...] em um universo caótico, impossível de dominar pelo pensamento, o homem está esmagado, é passivo, escravo; sua miséria salta aos olhos: decididamente ele não é mais do que uma besta desprezível. E se sente perdido, e está pronto a escutar docilmente a voz do eleito que se propõe a guiá-lo.

Contudo, o relativismo do pensamento de direita não se impõe sem problemas:

Se toda consciência é alucinada, toda ação interessada, como nos vão convencer de que eles possuem a verdade e que seus fins são objetivamente válidos? Levando o cinismo às suas últimas conseqüências, seríamos obrigados a concluir com Sade: "Todas as paixões têm dois sentidos, Juliette, um muito injusto, relativo à vítima, e o outro, singularmente justo, em relação àquele que a exerce". Mas então renunciamos a toda pretensão de justiça universal [...] (Beauvoir, 1972, p. 31).

No pensamento de direita, a história é descontínua, sem sentido, absurda, um "jogo ininteligível dos acasos" (Beauvoir, 1972, p. 44). Por sua vez, o ser humano é encerrado "[...] na sua existência empírica, não tendo entre si senão vínculos contingentes" (Beauvoir, 1972, p. 37).

Diante de um mundo caótico, de acasos e contingências, o anti-intelectualismo da direita também desconfia do papel da linguagem de revelar, racionalmente, a verdade objetiva. Nesse horizonte, ou se apela ao inefável, ou libera-se a linguagem para construçôes arbitrárias dos sujeitos. Por isso, diante do alto grau de liberdade, a estetização apresenta-se como um dos dogmas aristocráticos de direita sintetizados pela máxima: "[...] deve-se preferir a Beleza aos homens" (Beauvoir, 1972, p. 73).

A filósofa francesa também identifica que o pensamento de direita recorre ao argumento da natureza para justificar o pluralismo de raças, castas, etc. Nesse

Pro-Posiçóes, Campinas, v. 22, n. 3 (66), p. 177-193, set./dez. 2011 
sentido, as desigualdades não seriam injustas, pois "[...] a infelicidade dos homens não é um crime se ninguém é o seu autor” (Beauvoir, 1972, p. 103).

O pluralismo também efetua, para a autora, uma "dialética mutilada", na medida em que "[...] a tese e a antítese são imediatamente identificadas, sem que se opere a sua ultrapassagem conjunta para uma síntese superior. Tal é o método que a direita emprega deliberadamente para confundir as cartas e deter a História” (Beauvoir, 1972, p. 87). A identificação se dá em “[...] não se assemelhar aos outros. [...] em suma, provar que se é diferente" (Beauvoir, 1972, p. 95).

A intenção da elite é, portanto, de "[...] nos desiludir da política e desacreditar a idéia de revolução" (Beauvoir, 1972, p. 40). Assim, "Pluralista quando aborda as verdades dos outros, considera sua verdade como um absoluto" (Beauvoir, 1972, p. 56).

Pelos argumentos expostos, Beauvoir (1972, p. 107) reconhece que o pensamento burguês aparece como "um tecido de contradições" e de ecletismos. Contudo, não é possível criticá-lo sob esse aspecto, pois cairíamos na armadilha de julgá-lo apenas no âmbito da produção do conhecimento:

Sua ambivalência nos adverte que não nos deixemos enganar: todo pensamento se desenvolve, não entre as Idéias, mas sobre a terra, pondo a descoberto uma prática. Se o pensamento dos burgueses é tão embaraçado, é que há contradição entre os termos que o expressam e a prática (Beauvoir, 1972, p. 108).

Em outros termos, “[...] é impossível à burguesia assumir pelo pensamento sua atitude prática. Tal é a maldição que pesa sobre a sua ideologia” (Beauvoir, 1972, p. 110-111).

\section{Crítica ao multiculturalismo crítico}

Em que medida a análise do pensamento de direita realizada por Simone de Beauvoir pode contribuir para a elaboração de críticas ao multiculturalismo? É possível uma inferência direta entre o que ela disse e o que vivemos hoje?

Como dito, há um contexto histórico específico no qual o texto de Beauvoir é escrito, e há interlocutores igualmente específicos para os quais ela se dirige. Além disso, há algumas características do pensamento de direita de sua época não percebidas no multiculturalismo, como traços de pessimismo ou catastrofismo e recurso a argumentos biológicos (pelo contrário, esses argumentos são evitados). A indicação desses dois exemplos já sinaliza como um empreendimento falido qualquer transposição mecânica. Entretanto, salta à vista que alguns elementos indicados por Beauvoir no pensamento de direita se encontram atualizados em 
um discurso que atualmente se pretende de esquerda no campo das ciências humanas e da educação. Quais são esses pontos? Como um multiculturalismo que se pretende crítico pode conviver com tal incoerência? Os posicionamentos entre direita e esquerda política teriam alterado tanto assim? Ou, na verdade, a própria distinção se tornou obsoleta?

Para iniciar, consideramos essa última possibilidade fora de cogitação. Como argumenta Alain (apud Beauvoir, 1972, p. 13): "Quando me perguntam [...] se a separação entre os partidos de direita e de esquerda, entre homens de direita e homens de esquerda, tem ainda sentido, a primeira idéia que me ocorre é que quem me formula esta pergunta certamente não é um homem de esquerda". Feita essa ressalva, levantamos pontos que se mostram muito semelhantes entre o multiculturalismo e o pensamento de direita caracterizado por Beauvoir.

O primeiro deles diz respeito ao relativismo ontológico: não interessa a objetividade do real, mas a forma como os sujeitos dizem que esse real é. Essa postura idealista do pensamento de direita aparece de um modo específico no discurso multicultural. McLaren (2000) explica que a língua não é cópia do real, a língua fabrica a realidade. Nesse sentido, os objetos são internos ao discurso que os constitui. Assim, ganham proeminência as narrativas ou os relatos.

A noção de narrativa do multiculturalismo é tributária da proposição pós-moderna de Lyotard, para quem o discurso científico foi colocado como um saber superior perante os relatos tradicionais. Essa relação de desigualdade entre esses saberes, para ele, "É toda a história do imperialismo cultural desde os inícios do Ocidente" (Lyotard, 2000, p. 50). Segundo Lyotard, a ciência é uma narrativa como outra qualquer. Mas o que isso significa? Para ele, os relatos/narrativas são autolegitimadores, pois não recorrem a argumentos e provas para se afirmarem, ou seja, não possuem nenhum compromisso em dizer o que a realidade é. Conforme Lyotard, assim como os outros saberes, a ciência está baseada nas validades pragmáticas de um jogo de linguagem específico. A partir da heterogeneidade e da incomensurabilidade dos jogos de linguagem, mundos diferentes são estruturados. Portanto, na visão lyotardiana, todos os relatos são equivalentes, pois não haveria nenhum parâmetro externo, objetivo, a partir do qual eles poderiam ser avaliados.

Ora, ao se interditar qualquer referência ao em-si, o mundo se transforma em um constructo do sujeito (ou de acordos intersubjetivos). Aqui se apresenta o idealismo subjetivo do multiculturalismo. A luta contra uma narrativa que se impôs como superior se constrói a partir da noção de que, em princípio, há tantas ontologias quanto os discursos permitem; a igualdade que diferentes discursos possuem está no fato de que todos não passam de narrativas e, nesse sentido, não podem advogar compromisso com a verdade objetiva.

O relativismo e o ceticismo são posturas que decorrem inevitavelmente do relativismo ontológico, característico de várias correntes do pensamento con- 
temporâneo. Quando se abre mão de qualquer referente objetivo (considerado inexistente ou incognoscível), perde-se qualquer critério para avaliação de nossas crenças e, assim, todas ganham, igualmente, legitimidade.

Uma coisa é aceitar um "relativismo cultural" que respeita a
variedade da cultura humana; outra, inteiramente diferente,
é adotar um relativismo que transforma esses valores culturais
variados no único ou principal padrão de verdade, de modo
que a verdade passa a ser simplesmente o que se ajusta a um
dado sistema de crenças, ao invés de aquilo que descreve
fielmente o mundo que existe independentemente de nossas
crenças (Nanda, 1999, p. 100).

Entrelaçam-se a isso problemas de ordem ética e política, pois a relativização da verdade também envolve o relativismo da própria justiça. Como lembra Nanda (1999, p. 100, grifos da autora), "Compreendida inteiramente a partir de um dado ponto de vista, e sem nenhum padrão exógeno de verdade, é difícil entender como qualquer opinião possa ser errada ou qualquer prática, injusta”.

No horizonte, portanto, de uma retração teórica e do anti-intelectualismo no qual os conhecimentos elaborados são deslegitimados de sua natureza e igualados a qualquer outra narrativa, a educação escolar sofre um duro golpe. Na verdade, a escola plural pretende propiciar a crítica cultural e a hibridização cultural. $\mathrm{O}$ que significa a crítica cultural? Consiste em desvelar que a pretensão de superioridade de uma narrativa não se sustenta, tendo em vista que todas são igualmente legítimas para seus grupos. Por sua vez, o que implica a hibridização? Trata-se de encontros e desencontros entre narrativas, dos quais derivam novas narrativas e discursos culturais. O golpe sofrido pela educação escolar diz respeito, portanto, à redução de seu papel a um caráter sofístico. Em outras palavras, caberia à escola fomentar sofismas, depurados de qualquer pretensão de representar propriedades e qualidades objetivas do real e encerrados em conversaçôes infinitas, cujo interesse se circunscreve à própria poética do conversar e é impulsionado por ela (Paraíso, 2004).

Entretanto, a proposição multiculturalista se ergue a partir de argumentos que pretendem dizer o que a realidade é (ela é multicultural); que recomendam a forma correta e justa de tratar a natureza dessa realidade (o multiculturalismo); que condenam como simplistas e monoculturais os outros discursos que não compartilham suas teses; que criticam o imperialismo europeu e ocidental, mesmo tendo sido gestados em solo estadunidense (no caso do multiculturalismo) e em solo inglês (referimo-nos, especialmente, aos Estudos Culturais que se aproximam de vários aspectos defendidos pelo multiculturalismo crítico). Novamente se pode dizer, com Beauvoir, que se está diante de um "tecido de contradições". 
Além disso, existe um processo que necessita ser evidenciado. $\mathrm{O}$ multiculturalismo não é um aliado na luta ideológica contra o capitalismo, contra as desigualdades sociais. Apesar do inegável ímpeto democrático, anti-imperialista, anticolonial do multiculturalismo crítico, aqueles que mais se beneficiam de suas formulações são grupos conservadores cujos interesses podem, por um lado, ser criticados quanto à sua pretensão de verdade universal; porém, por outro, são preservados, na medida em que, mesmo assim, possuem sua verdade contextual, podem conviver e se mesclar com outras narrativas. Com isso, os objetivos políticos anunciados não podem ser alcançados pelos meios teóricos multiculturalistas. Desse modo, o multiculturalismo crítico alimenta toda sorte de dogmatismo e conservadorismo que supostamente combateria.

Talvez por isso Eagleton (1998, p. 34-35) afirme:

Apesar de toda a sua tão alardeada abertura para o Outro, o pós-modernismo pode se mostrar quase tão exclusivo e crítico quanto às ortodoxias a que ele se opóe. [...]. Trata-se de uma heterodoxia de todo ortodoxa, que como qualquer forma imaginária de identidade precisa de seus bichos-papóes e alvos imaginários para manter-se na ativa. [...] Embora inspire-se no espírito crítico, raras vezes o usa para tratar das próprias proposições.

Ademais, não podemos nos desviar do fato de que:

O capitalismo é a ordem mais pluralista que a história já conheceu, sempre transgredindo limites e desmantelando oposições, misturando formas distintas de vida e sempre excedendo a medida. Toda essa pluralidade, é preciso dizer, opera dentro de limites muito rigorosos [...] (Eagleton, 1998, p. 128-129).

Definir como eixo de luta a construção de uma sociedade mais plural, intercultural, híbrida é um modo sutil de subtrair da agenda política da esquerda a superação do capitalismo. Afinal, um capitalismo híbrido ou plural não deixa de ser capitalismo. Portanto, estamos diante de um pensamento de direita renovado e refinado em suas formulações, surpreendentemente abraçado por intelectuais que se pretendem de esquerda.

\section{Considerações finais}

O homem da direita despreza, como "primário", o saber sistematizado, que se comunica metodicamente e podese abeberar nos livros; só Ihe merece crédito a experiência 
vivida, que une singularmente um sujeito e um objeto que participam de uma mesma substância (Beauvoir, 1972, p. 54).

Diante da constatação mencionada no final do item anterior, quais desafios se apresentam aos professores e professoras que desejam não sucumbir à sedução de um discurso que se pretende progressista, mas, de fato, favorece posiçôes conservadoras? Para sugerir algumas pistas, propomos uma outra questão: sob a ótica desses professores, o que fazer, por exemplo, com o Monstro do Espaguete Voador?

A suposta teoria do Monstro do Espaguete Voador nos possibilita desvelar o grau de arbitrariedade na qual a escola atualmente se encontra. Nesse contexto, o multiculturalismo não nos oferece proteçôes. As narrativas mais simplistas podem ser sugeridas e, nesse caso, a partir de uma escola multicultural, o fato de considerá-las assim seria expressão de uma postura monocultural. Risíveis ou infundadas: nada disso interessa quando o objetivo é a poética do dizer! Quando o capitalismo revela a sua face mais perversa e sua impossibilidade de garantir uma vida digna a todos, qualquer teoria que assuma a tarefa de desvendar facetas do mundo objetivo é combatida e desacreditada. A interdição do conhecimento objetivo e a redefinição estética do papel da escola compóem o mesmo processo de fortalecimento do capitalismo contemporâneo.

Talvez, sem se dar conta, a experimentação do Monstro do Espaguete Voador tenha o mérito de mostrar que a pluralidade de narrativas desqualifica a escola e a intervenção dos professores, além de esfacelar o currículo escolar. Como forma de resistir a essa degradação da educação escolar, travestida de vanguardismo, necessitamos corroborar o apelo de Lukács (s.d., p. 15): “[...] a efetiva exigência que hoje se põe é retornar à efetividade existente em si”. Porém, efetivar tal dinâmica requer "[...] velar pela existência e pelo desenvolvimento da razão" (Lukács, 1972, p. 74) e reconhecer que, mesmo sendo a realidade mais rica e mais multiforme do que os melhores conceitos que se podem elaborar, o conhecimento pode nos aproximar do que ela seja, pode nos sinalizar suas propriedades, suas tendências. Portanto, o caráter aproximativo não conduz necessariamente a uma postura cética e relativista.

Por sua vez, a escola precisa, nesse horizonte, ratificar sua função de socializar o conhecimento elaborado e sistematizado (Saviani, 1991). Isso significa estimular uma atitude apaixonada, ao mesmo tempo passiva e ativa, de padecimento e de vigor diante das ricas e complexas objetivaçôes humanas. Por um lado, o desafio é fortalecer a única chance que os filhos e as filhas da classe trabalhadora têm de acessar conhecimentos elaborados; por outro, consiste em concretizar o processo sinalizado por Marx, no qual o conhecimento teórico passa a ter força material, isto é, ganha vida à medida que é apropriado e potencializa a luta contra a miséria e a barbárie social. 


\section{Referências bibliográficas}

AHMAD, A. Cultura, nacionalismo e o papel dos intelectuais. In: WOOD, E. M.; FOSTER, J. B. (Org.). Em defesa da história. Rio de Janeiro: Jorge Zahar, 1999. p. 5973.

BEAUVOIR, S. O pensamento de direita hoje. 2. ed. Rio de Janeiro: Paz e Terra, 1972.

CANDAU, V. M. Direitos humanos, educação e interculturalidade: as tensões entre igualdade e diferença. Revista Brasileira de Educação, Rio de Janeiro, v. 13, n. 37, p. 45$56,2008$.

CANEN, A. A pesquisa multicultural como eixo na formação docente: potenciais para a discussão da diversidade e das diferenças. Ensaio: avaliação e políticas públicas em educação, Rio de Janeiro, v. 16, n. 59, p. 297-308, 2008.

CANEN, A; ARBACHE, A. P.; FRANCO, M. Pesquisando multiculturalismo e educação: o que dizem as dissertações e teses. Educação e Realidade, Porto Alegre, v. 26, n. 1, p. 161-181, 2001.

CUNHA, L. A. Ensino religioso nas escolas públicas: a propósito de um seminário internacional. Educação e Sociedade, Campinas, v. 27, n. 97, p. 1235-1256, 2006.

CUNHA, L. A. A retomada de compromissos históricos aos 30 anos da ANPEd. Revista Brasileira de Educação, Rio de Janeiro, v. 13, n. 37, p. 168-172, 2008.

EAGLETON, T. As ilusões do pós-modernismo. Rio de Janeiro: Jorge Zahar, 1998.

HENDERSON, B. Church of the flying spaghetti monster. Disponível em: <http://www. venganza.org/>. Acesso em: 20 ago. 2008.

LUKÁCS, G. El asalto a la razón. 3. ed. Barcelona: Ediciones Grijalbo, 1972.

LUKÁCS, G. Existencialismo ou marxismo. São Paulo: Livraria Editora Ciências Humanas, 1979.

LUKÁCS, G. Neopositivismo. Tradução Mário Duayer. 19 p. Texto não publicado.

LYOTARD, J. F. A condição pós-moderna. 6. ed. Rio de Janeiro: José Olympio, 2000.

MACEDO, E. Currículo como espaço-tempo de fronteira cultural. Revista Brasileira de Educação, Rio de Janeiro, v. 11, n. 32, p. 285-296, 2006.

McLAREN, P. Multiculturalismo crítico. 3. ed. São Paulo: Cortez; Instituto Paulo Freire, 2000.

MOREIRA, A. F. B. A recente produção de pesquisa científica sobre currículo e multiculturalismo no Brasil (1995-2000): avanços, desafios e tensóes. Revista Brasileira de Educação, Rio de Janeiro, n. 18, p. 61-85, set./dez. 2001.

MOREIRA, A. F. B.; CANDAU, V. M. Educação escolar e cultura(s): construindo caminhos. Revista Brasileira de Educação, Rio de Janeiro, n. 23, p. 156-168, 2003.

Pro-Posiçóes, Campinas, v. 22, n. 3 (66), p. 177-193, set./dez. 2011 
NANDA, M. Contra a destruição/desconstrução da ciência: histórias cautelares do terceiro mundo. In: WOOD, E. M.; FOSTER, J. B. (Org.). Em defesa da história. Rio de Janeiro: Jorge Zahar, 1999. p. 84-106.

PARAÍSO, M. A. Pesquisas pós-críticas em educação no Brasil: esboço de um mapa. Cadernos de Pesquisa, São Paulo, v. 34, n. 122, p. 238-303, maio/ago. 2004.

PIECZARKA, J. C. O que é o Design Inteligente? Jornal da Ciência, Rio de Janeiro, 17 fev. 2005. Disponível em: <http://www.jornaldaciencia.org.br/Detalhe.jsp?id=25540>. Acesso em: 21 jun. 2008.

SAVIANI, D. Pedagogia histórico-crítica. São Paulo: Cortez; Campinas: Autores Associados, 1991.

Recebido em 09 de setembro de 2010 e aprovado em 31 de março de 2011. 
